\title{
High-resolution fission-track modelling of the German Naab
}

\author{
L. NOVAKOVA ${ }^{1,2^{*}}$, R. JONCKHEERE ${ }^{2}$, B. \\ WAUSCHKUHN $^{2}$, L. RATCHBACHER ${ }^{2}$
}

${ }^{1}$ Czech Academy of Sciences, Institute of Rock Structure and Mechanics, V Holesovickach 41, Prague, 182 09, Czech

Republic ( ${ }^{*}$ correspondence: lucie.novakova@irsm.cas.cz)

${ }^{2}$ TU Bergakademie Freiberg, Institute of Geology, Bernhardvon-Cotta-Straße 2, Freiberg, 09 599, Germany

Raymond.Jonckheere@geo.tu-freiberg.de Bastian.Wauschkuhn@geo.tu-freiberg.de Lothar.Ratschbacher@geo.tu-freiberg.de

It is questionable if apatite fission-track modelling is at all reliable. The Naab mountains on the western border of the Bohemian Massif present an interesting test case for addressing this fundamental problem. Their sediment cover since the Permian is well known, and tightly constrains the thermal histories of the dated basement samples [1]. We optimize the fission-track data through several non-standard procedures: (a) increasing the number of etched confined tracks by ion irradiation [2]; (b) step-etching to establish a rough sequence of relative formation ages of the measured tracks [3]; (c) measuring induced track lengths to determine the specific zero-length for modelling each sample [4]; (d) measuring the distances from the host track to the confined track axis to provide an estimate of the effective etch time of an individual track; (e) measuring confined track lengths in reflected and transmitted light, as well as their widths and orientations to the apatite $c$-axis to test the anisotropy of the fossil tracks [5].

We discuss the agreement and disagreement between the modelled thermal histories and the independent geological evidence, and the factors suspected of causing a mismatch.

[1] Vercoutere (1984) PhD thesis 191 pp.; [2] Jonckheere et al. (2007) Chem. Geol. 242, 202-217; [3] Jonckheere et al. (2017) Am. Min. 102, 987-996; [4] Carlson et al. (1999) Am. Min. 84, 1213-1224; [5] Donelick et al. (1999) Am. Min. 84, 1224-1234. 